declare that it was possible to separate easily the genuine cases from the dubious ones. "Those who evince a keen desire to recover and return to work are genuine, and will soon recover under appropriate medical treatment; those who show no inclination to recover, and make no effort toimprove, are malingerers or semi-malingerers." This statement would seem to me to be too dogmatic, but it undoubtedly contains much truth. There can be no doubt at all of the influence of the mind on the body, and where there is no inducement to return to work, or keen desire to do so, the illness will be proportionately prolonged.

Harley-street, $\mathbf{w}$.

\section{THE PERCUTANEOUS TUBERCULIN REACTION.} OBSERVATIONS ON 400 CASES.

BY A. J. BRUCE LFCKIE, M.D. EDIN., LATE RESTDENT MEDICAT OFFIOER, ROYAL MINERAL WATER HOSPITAL, BATH, ETC.

THE percutaneous diagnostic reaction, introduced by Moro and Doganoff, is a modification of the use of tuberculin ointment employed by Spengler as a therapeutic measure. Moro published his observations in 1908, and his method of procedure in June of the same year.

Tuberculin ointment.-The ointment which I employed consisted of tuberculin and anhydrous wool fat, according to Moro's formula This vehicle allows of the greatest concentration, and the lanoline is heated to $20^{\circ}$ or $30^{\circ} \mathrm{C}$. The ointment keeps well unless exposed to damp, when it decomposes. It is clear brown, transparent, and of characteristic odour.

Application of the test.-Usually the front of the chest was the site chosen, occasionally the abdomen if more convenient. A portion of ointment about the size of a pea was firmly rubbed in by the finger over about 4 square inches, the process taking 30 to 60 seconds; sometimes the skin was previously cleansed with ether. No dressing was applied. Bandelier and Roepke claim better results after cleansing the skin. In some cases simple ointments were used as controls, but without results.

The reaction.-On the area employed, as a rule, nothing can be observed for 12 hours. Usually under 24 hours, preceded by itching, small papules begin to appear, on an average in my cases from 14 to 16 hours. The papules are irregularly scattered and sometimes extend beyond the test area; they may be numerous or scanty. If the papules are well formed they may develop into pustules, with or without an intermediate vesicular stage. They are not infrequently surrounded by a zone of erythema, which may be pronounced and blotchy. The maximum development is attained in about 48 hours. Towards the end of the fifth day the crop begins to fade; the pustular elements dry up and small crusts are formed; the neighbouring skin becomes scaly with desquamation, which varies according to the intensity of the reaction. In a week alone remains a scaly patch with irregular brown pigmented areas. The rapidity of pustulation is more marked in children, whereas in other cases papulation may be the final stage.

Abnormal reactions.- Reactions occurring under 12 hours I have not observed. If, however, delayed beyond 24 hours I regard them as late; several of my cases were delayed until the eighth day.
Chlumsky refers to late reactions occurring on the fourth and fifth day. Of my cases 7 gave results on the third to eighth days. Petechial hæmorrhages were present in 4 of my cases; 2 of these cases were tuberculous subjects, 2 being clinically free from the disease. The petechiæ in 2 of these cases were the only evidence of reaction; in the other 2 cases the eruption accompanied them. In 1 case, howerer, the eruption did not appear until the eighth day; by this time the hæmorrhages had been absorbed. These may be compared with analogous phenomena met with in the cutaneous reaction.

Value of the test.- This test is the most simple and harmless of the tuberculin reactions. Numerous results greatly at variance have been obtained by different observers. Weil prefers this test to the other tuberculin methods; and Moro claims as good results in 338 children as with von Pirquet's reaction, regarding it as equal with the conjunctival test. Von Pirquet failed to get reactions with the ointment in children save in one exceptionally susceptible case. Heinemann considers it as good as the conjunctival test; but Chlumsky places little reliance upon it, obtaining 6 reactions out of 23 non-tuberculous children, whereas only 14 out of 24 tuberculous cases responded. Roepke and Bandelier obtained 54 positive results in 54 cases proved to be tuberculous by either demonstration of bacilli or injection of tuberculin. The latter procedure, however, can hardly be accepted as proof. Verge's experience in lupus led him to claim superiority for this test over injection, but a skin already the site of activity readily responds.

These data will serve for comparison with the results I have obtained in 400 cases. Of this series, 96 cases presented unquestionable signs of tuberculous disease, comprising various lesions. of these cases 33 reacted, leaving 63 tuberculous cases devoid of response. Out of 304 cases clinically free from the disease 38 gave results; 9 of them were doubtful, 4 of which reacted. There is an unavoidable fallacy in many cases, as clinical freedom is no proof of absolute freedom. In non-tuberculous subjects Moro's experience coincides with my own, fewer results being obtained than with the scarification method. Patterson made similar observations, but regards it as equal in value with the ophthalmic test.

In my series 12 per cent. of reactions occurred in non-tuberculous individuals and only 34 per cent. in subjects of the disease. Fewer results are obtained in tuberculous individuals than with the von Pirquet method, but in non-tuberculous cases there is a striking contrast, 36 per cent. of results being obtained with the scarification method. Females react more readily than males, 80 of my positive results being in females; and children respond more frequently than adults. The age period is also of significance; nearly all the reactions occurred both in tuberculous and nontuberculous cases under the age of 20 .

In pulmonary tuberculosis the results were bad; 34 out of 43 cases entirely failed to respond. In osseous tuberculous lesions only half the cases reacted, although Moro claims particular accuracy in lesions of this nature. The majority of cases of tuberculous peritonitis failed. Out of 21 cases where signs of morbidity were wanting the reaction appeared in 4: but the rheumatic cases did not give the large percentage of reactions which I have observed with the von Pirquet test. All the 
cases of enteric fever and pleural effusion gave negatice results; 2 of the effusion cases had definite tuberculous signs.

The best reactions are to be found in well. nourished individuals, especially children; here Chlumsky is in agreement. Old-standing cases and old subjects usually fail; this is possibly due to the inability of the skin to react, resulting from either chronicity of toxæmia or from trophic changes in the skin concurrent with advancing years. The greater susceptibility of the female sex points to delicacy of the skin as a factor. I also made observations to ascertain whether fair individuals, as opposed to those possessing a larger share of pigment, were more liable to respond, but no relation exists. It is well established that increase in dose of tuberculin injections may convert a failure into a response; both the skin and conjunctival reactions might give better results if the dose were regulated. Among the tuberculous cases all the positive results except 5 occurred under the age of 14 years, the majority of failures occurring between 15 and 40 years of age.

In order to form a more close comparison between the ron Pirquet reaction and the Moro test $I$ applied both in a series of 132 cases. Of these cases 51 were definitely tuberculous, but only 13 out of these reacted to both, and 20 failed to respond to either, but I have never observed a tuberculous case which reacted to the ointment fail also to react to the ron Pirquet method. Moro reports a similar experience. Out of my cases clinically free from tuberculosis 6 responded to both tests, 50 failed to react to either. Whereas 23 reacted to the scarification only 2 non-tuberculous cases gave results with the ointment only. These results may be more clearly shown in tabular form :-

\section{Cases to which Two Tests were Applied.}

Tuberculous eases giving von PIrquet and Moro reactions ... $\quad . .13$

$\begin{array}{llllllll} & \| & \| & \text { von Pirquet reaction only } & \ldots & \ldots & \ldots & 18\end{array}$

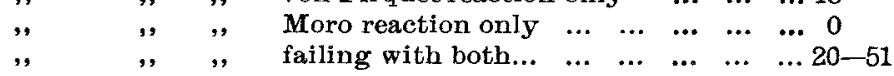

Non-tuberculous cases giving von Pirquet and Moro reactions ... 6

$$
\begin{aligned}
& \begin{array}{llllllll}
, & \quad & \quad & \quad & \text { von Pirquet reaction only } & \ldots & \ldots & 23 \\
, & \quad, & \text { Moro reaction only } & \ldots & \ldots & \ldots & \ldots & 2
\end{array}
\end{aligned}
$$

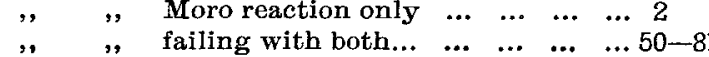

From the above it is clear that the von Pirquet test gives a larger number of reactions among tuberculous subjects than the ointment test, but at the same time it gives a much larger number of false results among non-tuberculous individuals. These two skin reactions are much inferior to the ophthalmic test, which gives a large percentage of true results, whilst reactions in non-taberculous subjects are not very frequent.

Conclusions.- 1 . The ointment test is exceedingly inaccurate. 2. It does not give nearly so many reactions in non-tuberculous cases as the von Pirquet test. 3. Most reactions are obtained in women and children. 4. It is of no value in prognosis. 5. It more often fails in tuberculous cases than the cutaneous reaction. 6. Late reactions have no clinical significance. 7. Tuberculous cases which respond to the ointment also react to the von Pirquet method. 8. Pyrexia does not interfere with the reaction. 9. The test is free from danger.

Biblzography.-Bandelier and Roepke : Tuberculin in Diagnosis and Treatment. Chlumsky: Brit. Med. Jour., 1910, vol. i. Doganoff : Medizinische Wochensehrift, 1908, No. 11. Moro : New York and Mhiladelphia Medical Journal, 1908. Patterson : Archives of Internal Medicine, 1909. Verge: Brit. Med. Jour., 1910, vol. ii.

Bath.

\section{A CASE OF POST-OPERATIVE OSTEO- MYELITIS OF THE FRONTAL BONE. \\ RECOVERY AFTER WIDE REMOVAL OF THE DISEASED BONE.}

BY W. G. PORTER, M.B., B.Sc. Edin., F.R.C.S. EuIN, SURGEON, FAR AND THROAT DEPARTMENTS, ROYAL HOSPITAL FOR SICK CHILDREN, AND EYE, EAR, AND THROAT INFIRMARY, EDINBURGH.

OSTEOMYELITIS of the frontal bone is not a rery uncommon complication of frontal sinus suppuration, but it is an extremely dangerous one. Dr. D. Mackenzie, ${ }^{1}$ in a recent exhaustive account of the condition, states that in 20 post-operative cases which he collected he had found no case recorded in which the patient had recovered; while in spontaneous cases the results were not so bad, 7 having recovered out of 21 cases after appropriate surgical treatment. The following case is, so far as I know, the first post-operative case in which recovery has ensued, and it accordingly seems desirable to give a somewhat detailed account of it.

The patient, a married woman aged 46, was referred to me from the Eye Department of the Edinburgh Eye, Ear, and Throat Infirmary by Dr. J. V. Paterson. She complained of double vision and a swelling just above the right eyeball towards the external canthus, and there was also definite proptosis. After examination a diagnosis was arrived at of empyema of the right frontal sinus and ethmoidal labyrinth, with orbital abscess.

Killian's operation was performed on May 14th, 1912. The frontal sinus was found to be filled with creamy mucopus (pure culture of hæmolytic long-chained streptococcus obtained), but the lining membrane was not thickened; hence it was thought that the case was one of infected mucocele. The floor of the sinus had given way rather far back, and pus was lying on the orbital periosteum, which at this spot was covered with granulations; there was a very well-marked orbital extension--it was fully an inch and a half in depth. In smoothing off the bone close to the intersinus septum the latter was unfortunately cracked, exposing the sinus on the opposite side. The wound was entirely closed and healed by first intention. Three weeks later the upper eyelid became codematous; the wound was reopened and a quantity of pus evacuated. The discharge continued in spite of the administration of an autogenous vaccine and of endeavours to obliterate the sinus by pressure.

A second operation was performed on Oct. 3rd, 1912. The inner end of the bridge was removed, and a sinus was traced to the hole in the septum, where pus was seen coming from the left frontal sinus. The outer part of the right frontal sinus was obliterated by dense fibrous tissue, as was the opening into the nose. A Killian's operation was thereupon performed on the left frontal sinus, which also had a deep orbital extension. The inner part of the incision was left open after the operation, sutures being passed, but not tied for 48 hours, there being then no discharge. The wound healed at once, but a few days later the upper eyelid became swollen, and pain was felt at night; there was, however, no pyrexia.

On Nov. 11th the swelling became more marked, and there was great tenderness on pressure over the bridge. The wound was reopened; the inner end of the bridge was divided, and it was then found to be loose, a sequestrum being removed which consisted of the outer end of the bridge and the upper margin of the orbit external to it. (Fig. 1.) No pus was evacuated. The wound was left freely open and loosely packed. The pain was not relieved by the operation and the upper eyelid remained swollen. The temperature varied between $98.4^{\circ}$ and $992^{\circ} \mathrm{F}$.

On Nov. 17th cedema of the skin was noted over the frontal sinus; this spread rapidly, and on the 20 th extended up to the hair margin and across the middle line; there was, however, very little discharge from the wound, which was still kept widely open. It was believed that osteomyelitis had set in, and wide removal of the frontal bone appeared to

1 Journal of Laryngology, January, February, and March, 1913. 